\title{
Preference between predictable and unpredictable administrations of carbon dioxide-enriched air
}

Carl Wilbourne Lejuez

West Virginia University

Follow this and additional works at: https://researchrepository.wvu.edu/etd

\section{Recommended Citation}

Lejuez, Carl Wilbourne, "Preference between predictable and unpredictable administrations of carbon dioxide-enriched air" (1999). Graduate Theses, Dissertations, and Problem Reports. 3133.

https://researchrepository.wvu.edu/etd/3133

This Dissertation is protected by copyright and/or related rights. It has been brought to you by the The Research Repository @ WVU with permission from the rights-holder(s). You are free to use this Dissertation in any way that is permitted by the copyright and related rights legislation that applies to your use. For other uses you must obtain permission from the rights-holder(s) directly, unless additional rights are indicated by a Creative Commons license in the record and/ or on the work itself. This Dissertation has been accepted for inclusion in WVU Graduate Theses, Dissertations, and Problem Reports collection by an authorized administrator of The Research Repository @ WVU.

For more information, please contact researchrepository@mail.wvu.edu. 
Preference Between Predictable and Unpredictable Administrations

of Carbon Dioxide-Enriched Air

\author{
Carl Wilbourne Lejuez \\ Dissertation submitted to the \\ Eberly College of Arts \& Sciences \\ at West Virginia University \\ in partial fulfillment of the requirements \\ for the degree of \\ Doctor of Philosophy \\ in \\ Adult Clinical Psychology \\ Georg H. Eifert, Ph.D., Chair \\ Daniel W. McNeil, Ph.D. \\ B. Kent Parker, Ph.D. \\ Jerry B. Richards, Ph.D. \\ M. Katherine Shear, M.D. \\ Department of Psychology \\ Morgantown, West Virginia \\ 1999
}

Keywords: Predictability, Panic Disorder, Anxiety, Choice, Carbon Dioxide, Humans Copyright 1999 Carl Wilbourne Lejuez 


\section{ABSTRACT \\ Preference Between Predictable and Unpredictable Administrations of Carbon Dioxide-Enriched Air}

\section{Carl Wilbourne Lejuez}

Predictability of panic attacks has been identified as an important factor in the development, maintenance, and treatment of panic disorder. Although animal studies typically have found a preference for signaled (predictable) over unsignaled (unpredictable) aversive events, results with human participants have been less clear. Because preference for predictability has a wide range of clinical implications, we examined human preference for predictability in a biological challenge paradigm. Further, we examined the differential effects of predictability as a function of anxiety sensitivity and gender. In general, females showed a significantly greater preference for predictability compared to males, as did high anxious participants compared to their low anxious counterparts. Specifically, high anxious females showed the greatest preference for predictability, high anxious males and low anxious females showed moderate preference for predictability, and low anxious males were indifferent. Although the results suggest the necessity of considering individual difference variables such as gender and anxiety sensitivity, support is provided for the use of prediction testing and other strategies to enhance an individual's prediction of panic attacks in the treatment of panic disorder. 


\section{Acknowledgements/Dedication}

Great appreciation goes to Georg H. Eifert for invaluable assistance in the current project, as well as serving as my advisor over the last four years. Although there are several valuable skills that Georg has tried to teach me, I have taken the greatest pain to emulate his ability to prioritize and not sweat the small stuff.

Thanks also goes to Daniel W. McNeil, not only for serving on my committee, but more importantly for modeling upstanding behavior in both professional and personal interactions. Further, he has always been a good sport about my offbeat sense of humor, showing that one can be successful without being uptight. Thanks also to Jerry Richards, also a committee member, who approached this project, as he does most projects, with an interest and critical approach that was inspiring. It has been such a pleasure to work with someone who loves his work as much as Jerry does.

Appreciation goes to the other members of my committee, Kent Parker and Katherine Shear. Special thanks to Michael Zvolensky who has been a springboard for ideas and a valuable intellectual resource, as well as Michelle Heffner who did much of the dirty work including scheduling subjects. Further, I am indebted to John Sorrell for being a great friend and source of strength in tough times, and Derek Hopko who has provided a constant stream of free sodas and junk food, in addition to friendship, that have served to keep me energized throughout the creation of this document.

Finally, I thank my family, and especially my mother, for constant support throughout this long education process. It would be an understatement to say that I could not have done it without her. 
The research reported in this dissertation was funded by grants from the West Virginia University Department of Psychology Alumni Fund and the Eberly College of Arts and Sciences. 
Table of Contents

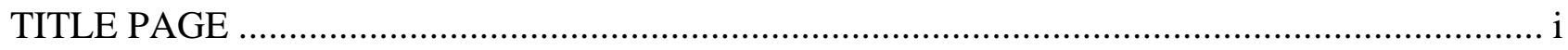

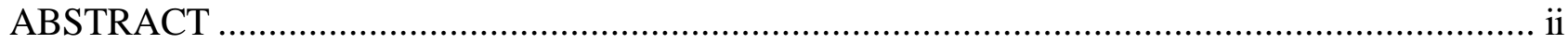

ACKNOWLEDGEMENTS/DEDICATION .....................................................................ii

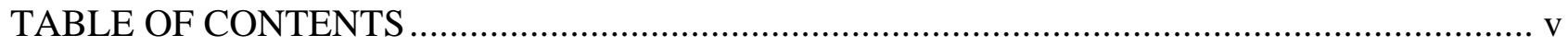

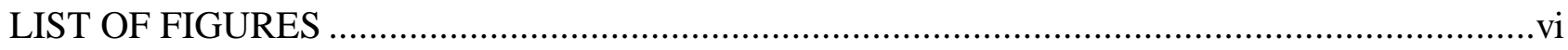

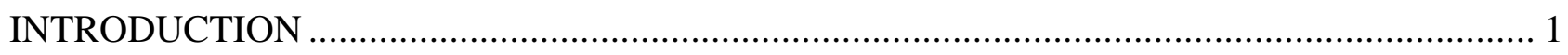

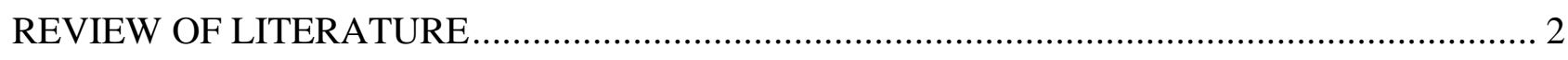

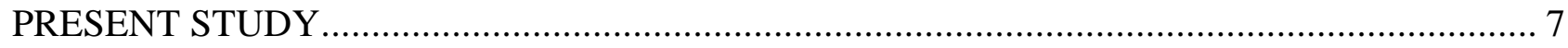

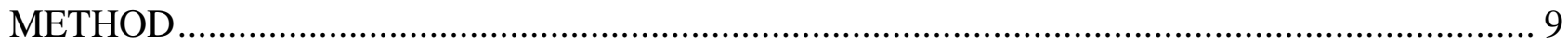

RESULTS

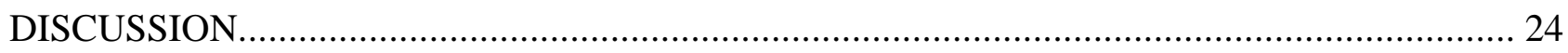

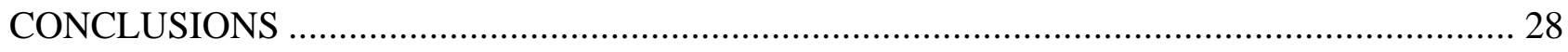

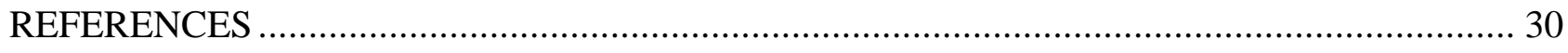

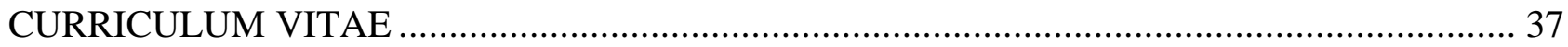




\section{List of Figures}

Figure 1. Number of choices of the predictable $\mathrm{CO}_{2}$ alternative in Phase 2, as a function of anxiety sensitivity (ASI) and gender. Bars on the left side of the Figure represent high anxiety sensitive (n $=20)$ and low anxiety sensitive $(n=20)$ participants. Bars on the right side of the Figure show the same participants grouped according to female $(n=20)$ and male $(n=20)$ gender. Scores ranged from 0 to 18, with lower scores indicating preference for unpredictability and higher scores indicating preference for predictability. The horizontal dashed line crossing the $y$-axis at the value 9 indicates indifference. Standard error of the mean for each group is indicted by the vertical line crossing each bar.

Figure 2. A further breakdown of the data provided in Figure 1, with choice scores shown for low anxiety sensitive (ASI) males, low anxiety sensitive females, high anxiety males, and high anxiety females. Standard error of the mean for each group is indicted by the vertical line crossing each bar.

Figure 3. Scores on a visual analog scale (VAS) completed at the conclusion of Phase 1, comparing preference between predictable and unpredictable trials, as a function of anxiety sensitivity (ASI) and gender. Bars in the left panel represent high anxiety sensitivity $(\mathrm{n}=20)$ and low anxiety sensitivity $(n=20)$ participants. Bars in the right panel show the same participants grouped according to female $(n=20)$ and male $(n=20)$ gender. Scores range from -50 to +50 , with lower scores indicating preference for unpredictability and higher scores indicating preference for predictability. The y-axis at the value 0 indicates indifference. Standard error of the mean for each group are indicted by the vertical line crossing each bar. 
Figure 4. A further breakdown of the data provided in Figure 3, with visual analog scales scores shown for low anxiety (ASI) sensitive males, low anxiety sensitive females, high anxiety sensitive males, and high anxiety sensitive females. Standard error of the mean for each group are indicted by the vertical line crossing each bar. 
Introduction

Predictability of threatening events is considered to be a key variable in the development and maintenance of anxiety (see Foa, Zinbarg, \& Rothbaum, 1992; Mineka \& Zinbarg, 1996, for reviews). Specifically, unpredictable threatening events are thought to produce greater anxietyrelated distress compared to predictable events (cf. Mineka \& Kilstrohm, 1978). Although predictability is relevant to anxious responding across many anxiety disorders (Armfield \& Mattiske, 1996), perhaps it is most crucial for recurrent uncued and unexpected panic attacks as they occur in Panic Disorder (PD; Barlow, Chorpita, \& Turovsky, 1996).

Predictability may be relevant to PD in a number of clinically important ways. First, in regard to symptom presentation, degrees of predictability are used to distinguish between different types of fearful/panic responding (Klein \& Klein, 1989). For example, panic attacks are categorized, in part, based upon whether identifiable internal or external events are antecedent and occur in close temporal proximity to an attack (Barlow, 1988). Second, experience with unpredictable events may serve to elevate anxiety-related responding and therefore function as a process variable in the onset and progression of panic pathology (Craske, Glover, \& DeCola, 1995). Third, a widely used empirically-validated cognitive-behavioral treatment manual for PD (Mastery of your Anxiety and Panic-II; MAP-II; Barlow \& Craske, 1994), contains a module focusing on the predictability of panic attacks. For example, the MAP-II incorporates several exercises that are aimed at helping the patient to identify causes (cues) of unexpected panic attacks. These exercises are intended make the unexpected become more predictable, based on the assumption that this will result in a decrease in anxiety (Rachman, 1990; Rachman \& Lopatka, 1986). 


\section{Empirical Evidence}

Despite the hypothesized association between predictability and PD in humans, the preponderance of empirical evidence that articulates the psychological functions of predictability is based upon research with infrahumans (cf. Minor, Dess, \& Overmier, 1991). In a representative study, Seligman (1968) found that operant behavior was disrupted during auditory tone presentations when shock had reliably followed that tone (Predictable Group). When the tone was absent, operant behavior returned to its normal level. In contrast, operant behavior was disrupted at all times for rats exposed to uncorrelated shock and tone presentations (Unpredictable Group). In addition, six of the eight rats in the Unpredictable Group developed stomach ulcers, compared with none of the rats in the Predictable Group (see Estes \& Skinner, 1941; Seligman \& Meyer 1970; Weiss, 1968; 1970, for similar studies).

To explain the benefits of predictability regarding an aversive stimulus, Seligman formulated the safety-signal hypothesis. This hypothesis suggests that when a stimulus is a reliable predictor of the occurrence of an aversive stimulus, the presence of that stimulus signals danger. Conversely, the absence of the warning stimulus signals safety. Alternatively, the Preparatory Response Hypothesis (Perkins, 1955; Perkins, Levis, \& Seyman, 1963), suggests that predictability provides the organism with an opportunity to employ strategies to minimize the resulting pain. Thus, preparatory responses may (a) limit contact with the aversive stimulus via strategies such as postural adjustments or (b) reduce the effects of the stimulus through less direct coping strategies such as distraction. Although the two theories suggest different mechanisms by which predictability affects anxious responding, no conclusive evidence has supported one theory 
over the other, and both may be applicable to varying degrees. It may be that both processes mediate the effects of predictability (Fanselow, 1980).

Although predictability has been studied with human participants in laboratory studies in a similar manner as infrahuman research, there is little consensus regarding its effects (Miller \& Grant, 1979). For example, several studies have found humans will choose predictable aversive stimuli over similar aversive stimuli that are unpredictable (Badia, McBane, Suter, \& Lewis, 1966; Jones, Bentler, \& Petry, 1966; Maltzman \& Wolff, 1970), whereas others have found no difference (Furedy \& Doob, 1971a; 1971b; 1972). Further, these relatively unreliable findings are apparent across a variety of anxiety-related response domains. For example, research has found self-reported pain and distress are (a) greater to predictable stimuli (Lovibond 1968; Maltzman \& Wolff, 1970); (b) greater to unpredictable stimuli (Averill \& Rosenn, 1972; Furedy \& Chan, 1971; Furedy \& Klajner, 1972) and (c) equal for predictable and unpredictable stimuli (Bowers, 1971). Inconsistent results also have been found in the natural environment. Two studies showed that individuals with predictable panic attacks reported greater distress and more panic symptoms during an attack than did individuals with unpredictable attacks (Margraf, Taylor, Ehlers, Roth, \& Agras, 1987; Street, Craske, \& Barlow, 1989). Craske et al. (1995) also found that unpredictable panic attacks resulted in greater concern about future panic attacks, but they also found that predictable attacks were related to an increase in avoidance behavior.

Perhaps one reason for the difficulty in determining the effects of predictability in the laboratory is that predictability has infrequently been studied in a manner that is relevant to PD, particularly in laboratory settings. That is, nearly all of the experimental investigations with humans have utilized aversive tactile stimulation as the aversive preparation, a procedure that 
produces acute, peripheral pain that differs from the types of bodily sensations characteristic of panic attacks. One way to address this concern is to employ biological challenge procedures that can produce responses that mimic escalating autonomic activity, a defining feature of panic attacks and PD. Carbon dioxide-enriched air $\left(\mathrm{CO}_{2}\right)$ is one panic provocation strategy that can produce repeated episodes of abrupt autonomic arousal and the repeated presentation of high concentrations of $\mathrm{CO}_{2}$ (range: $13.5 \%-35 \% \mathrm{CO}_{2}$ ) is a well-established provocation procedure for PD and related nonclinical populations (see Lejuez, Forsyth, \& Eifert, 1998). On a more basic level, $\mathrm{CO}_{2}$ has been established as an aversive stimulus that individuals will actively work to avoid (Lejuez, O'Donnell, Wirth, Zvolensky, \& Eifert, 1998), and it has been shown to produce elevated reports of anxiety (e.g., Beck, Shipperd, \& Zebb, 1996; Zvolensky, Eifert, Lejuez, \& McNeil, in press; Zvolensky, Lejuez, \& Eifert, 1998).

Additionally, the insensitivity of the dependent measures used within laboratory studies of predictability may have led to unclear results. For example, Lejuez (1997) used a behavioral disruption procedure similar to Seligman (1968), and found little difference in the disruption of a simple operant task (i.e., a plunger pull) in the presence of predictable and unpredictable administrations of $20 \% \mathrm{CO}_{2}$. Although other explanations may be used to interpret this lack of findings, the standard conditioned suppression paradigm used with rats may be too simplistic to produce differential results with humans.

Much of the animal work examining predictability has used the conditioned suppression paradigm, but a somewhat smaller body of work has found similar results using a forced-choice paradigm (e.g., Badia, Harsh \& Abbott, 1979; Badia, Harsh, Coker, \& Abbott, 1976). In this paradigm, an organism is given the choice between experiencing predictable or unpredictable 
aversive stimulation, with the primary dependent measure being the distribution of these choices. Such a procedure may be more sensitive than a conditioned suppression procedure because, by design, it forces a choice between the two alternatives.

Using a forced-choice $\mathrm{CO}_{2}$ paradigm, Lejuez, Zvolensky, Eifert, Sorrell, and Shear (1999) examined choice between predictable and unpredictable administrations of $20 \% \mathrm{CO}_{2}$ in three individuals with PD. Using a single-subject design, each individual was exposed to an average of fourteen days of repeated trials in which a button press determined whether or not $\mathrm{CO}_{2}$ would be signaled by a tone. The results showed that preference for predictability differed across participants. Specifically, one participant showed a reliable preference for onset predictable administrations, whereas two participants did not.

The results from Lejuez et al. (1999) suggest that not all persons may prefer predictable over unpredictable stimuli. For example, even if predictability has uniform benefits for coping with anxiety-related events, it is not known if individuals will engage in positive coping strategies to maximize the benefits of this variable, as an individual's biological disposition and/or learning history with aversive events may be more suited to adopting a strategy of helplessness in such situations (cf. Seligman, 1968). Thus, in certain situations, individuals may not want to know when an aversive event will begin, especially when direct methods for controlling the event either are not available (e.g., skill deficit) or difficult to utilize. If so, such results would support the incorporation of prediction-based exercises in the psychological treatment of pathological anxiety, but only on an individualized basis (Eifert, Schulte, Zvolensky, Lejuez, \& Lau, 1998). 
Situational and Individuals Difference Factors

Given that the effects of predictability may vary across individuals, it is important to identify factors that may underlie this difference. One such factor is anxiety sensitivity, defined as the fear of the consequences of anxiety symptoms (McNally, 1994). Persons with PD report particularly high ASI scores relative to normals and persons with other anxiety disorders, and high ASI scores predict the future occurrence of panic attacks in persons without a prior history of panic (Schmidt, Lerew, \& Jackson, 1997). Related to predictability, Janis (1958) found that prior to experiencing an aversive and anxiety provoking medical procedure, the provision of information to the patient regarding the procedure was positively correlated with recovery. Janis also suggested that for individuals with low levels of preoperative fear, the benefit of information was reduced. Based on this finding, it could be hypothesized that individuals with high levels of anxiety sensitivity would prefer future aversive bodily events such as a panic attack to be predictable (i.e., information regarding the onset of the attack) as opposed to unpredictable, whereas a similar preference may not occur for individuals with low anxiety sensitivity.

Gender is a second factor that may mediate the effects of predictability. Females are more likely than males to assess risk and actively seek out information regarding unpleasant events (Blanchard, Griebel, \& Blanchard, 1995). This hypothesis was supported in a laboratory study by Grusec and Grusec (1971). Participants were told that they would be exposed to either a pleasant (receipt of money) or unpleasant (receipt of electric shock) event and given an envelope that revealed which would occur. The experimenter then left the room and told the participants that he/she would return in $20 \mathrm{~min}$. The dependent measure was the latency from when the experimenter left the room until the participant opened and read the contents of the envelope, 
which was significantly shorter for females than males. Increased information seeking in females also has been observed in the natural environment. For example, the higher number of female patients diagnosed with a psychological disorder has been linked to greater information seeking (e.g., more frequent clinic visits) regarding symptoms (Cleary, Burns, \& Nycz, 1990; Corney, 1990). Females also have been found to engage in more extensive information seeking behavior regarding physical symptoms (Knight \& Elfenbein, 1996) including those indicative of a serious disease such as HIV infection (Wolitski, Bensley, Corby, Fishbein, \& Galavotti, 1997).

Although the exact mechanisms underlying a gender difference in information seeking are unclear, Blanchard et al., (1995) have provided evidence that both behavioral and physiological mechanisms regarding stress and threat play an important role. Additionally, a gender difference may at least be partially influenced by differential levels of anxiety sensitivity and general anxietyrelated concerns. Specifically, females report a greater number, and more severe, fears than males (Kirkpatrick \& Berg, 1982). Further, compared to males, females generally score higher on the ASI (Peterson \& Reiss, 1992) and provide higher self-ratings of the intensity of fears related to physical threat (Stewart, Taylor, \& Baker, 1997). As such, anxiety sensitivity may play a role in gender-related preference for predictability, however, the degree of influence is unclear and in need of further investigation.

\section{Present Study}

Given the hypothesized clinical significance of predictability and the absence of supportive data with humans, the primary purpose of the present study was to determine whether individuals would prefer predictable over unpredictable administrations of $\mathrm{CO}_{2}$. In the context of a discretechoice procedure, participants were given the choice between experiencing presentations of $\mathrm{CO}_{2}$ 
preceded by a warning signal and otherwise similar presentations that were not preceded by a warning signal. As additional dependent measures comparing predictable and unpredictable $\mathrm{CO}_{2}$, physiological responses as well as estimates of self-reported preference, unpleasantness, and anxiety were examined.

The second purpose of the present study was to determine whether preferences are related to anxiety sensitivity and/or gender. Because (a) $\mathrm{CO}_{2}$ has been shown to produce greater reactivity in individuals scoring high on the Anxiety Sensitivity Index (ASI; Reiss, Peterson, Gursky, \& McNally, 1986) than low scorers (Eke \& McNally, 1996) and (b) information about aversive events is most useful when anxiety levels are elevated, we expected that participants with high anxiety sensitivity would have greater preference for predictable over unpredictable $\mathrm{CO}_{2}$ presentations than low ASI participants. Additionally, we expected unpredictable $\mathrm{CO}_{2}$ to produce high levels of self-reported unpleasantness and anxiety as well as greater physiological arousal than predictable $\mathrm{CO}_{2}$ in the high anxious participants, than the low anxious participants. Furthermore, the magnitude of these effects, irrespective of predictability, was expected to be greater for the high anxious participants, compared to their low anxious counterparts.

Based on the greater need for information seeking in females compared to males, and the differences in anxiety sensitivity and overall anxiety-related concerns, females were expected to differ from males in the same way that high ASI individuals differed from low ASI individuals. Further, the interaction of Anxiety sensitivity and gender will be examined, with an effort to partial out independent influence of the two variables. 


\section{Method}

\section{$\underline{\text { Participants }}$}

Participants were 40 undergraduate students $(\underline{\mathrm{M}}=19.1$ years; $\underline{\mathrm{SD}}=1.4)$ at West Virginia University in introductory psychology classes. In total, 623 students completed the ASI screening. In this sample, males recorded a mean ASI score of $17.8(\underline{\mathrm{SD}}=7.2)$ and females recorded a mean ASI score of $20.8(\underline{\mathrm{SD}}=8.4)$. Ten males scoring one standard deviation above the male sample mean $(>=25)$ and ten females scoring one standard deviation above the female sample mean $(>=$ 29) comprised the high ASI group, whereas ten males scoring one standard deviation below the male sample mean $(<=11)$ and ten females scoring one standard deviation below the female sample mean $(<=12)$ comprised the low ASI group. This gender stratification procedure was used to control for the confounding of gender and anxiety sensitivity level, as females score higher on the ASI compared to males (Peterson \& Reiss, 1992). The mean ASI scores across the four groups were $8.7(\underline{\mathrm{SD}}=2.4)$ for low ASI males, $9.5(\underline{\mathrm{SD}}=1.9)$ for low ASI females, $30.8(\underline{\mathrm{SD}}=$ 4.6) for high ASI males, and 38.8 ( $\underline{\mathrm{SD}}=7.9)$ for high ASI females. Concerning ASI score across gender, high ASI males and females differed significantly $(\underline{F}(1,19)=7.73, \underline{p}=.012)$. The distribution of these scores in relation to their striated mean, however, was equivalent across the two groups. Specifically, for both males and females, 5 were one SD above, 3 were 2 SD above, 2 were 3 SD above their respective means. Low ASI males and females did not differ. Further, collapsing across low and high ASI categories, ASI scores for males and females did not differ. Potential participants were first screened for past/present anxiety-related psychological concerns using the anxiety disorders section of the Structured Clinical Interview for DSM-IV (SCID-IV; First, Spitzer, Gibbon, \& Williams, 1996). All interviews were completed by a SCID- 
IV certified rater. Participants meeting criteria for a past or present anxiety disorder were excluded. Second, participants completed a brief medical screening interview previously employed in our laboratory (e.g., Forsyth \& Eifert, 1998), and excluded from the study if they reported past or present angina, asthma, cardiovascular problems, epilepsy, hypertension, or a history of such problems in their first-order families. In total, three participants were excluded for a personal history of asthma. Participants were asked to refrain from strenuous physical exercise and the consumption of caffeine 12 hours prior to experiment, as such activities may elevate somatic activity and thereby impede accurate physiological assessment. All participants received course work extra credit for their participation in the experiment.

Materials and Apparatus

Sessions were conducted in a 2-m X 6-m experimental room in the Department of Psychology at West Virginia University. Participants sat at a desk supporting a Laser 48633SX computer, a Laser SVGA color monitor, a mouse, and a keyboard. The experimenters sat in an adjacent room containing an apparatus for providing participants with either room air or a mixture of $20 \%$ carbon dioxide-enriched air $\left(20 \% \mathrm{CO}_{2}, 21 \% \mathrm{O}_{2}, 59 \% \mathrm{~N}_{2}\right) \cdot \mathrm{CO}_{2}$ was stored in a $101-\mathrm{cm}$ cylinder and fed through a 5-cm X 5-cm hole via aerosol tubing from the experimenter room to a positive-pressure downs C-pap mask worn by the participant. An automated apparatus, described in Lejuez, Forsyth, and Eifert (1998), was used for $\mathrm{CO}_{2}$ delivery. A one-way mirror allowed the experimenters to observe all session events.

Physiological assessment. A Coulbourn Modular Polygraph was used to digitally record physiological data on-line at a sample rate of 10 samples/sec across all channels using Coulbourn's Lablinc polygraph software (High Speed Videograph). All physiological channels 
were calibrated on-line prior to sampling. Physiological responses were sampled using disposable $8 \mathrm{~mm}$ diameter $\mathrm{Ag} / \mathrm{AgCl}$ electrodes which were coated with a .05 molar concentration of $\mathrm{NaCL}$ and attached to the skin surface with concentric adhesive collars. Skin conductance levels (SCLs) were directly recorded in microsiemens $(\mathrm{mS})$ in an AC coupling mode with a Coulbourn S71-23 isolated skin conductance coupler that provided a constant 0.5 volts across the electrodes. Electrode placement followed a standard bipolar palmar configuration on the participant's nondominant hand. To assess for differential breathing processes during the experiment, we assessed expired levels of $\mathrm{CO}_{2}\left(\mathrm{PCO}_{2}\right)$ using an Ohmeda 5200 (BOC Health Care) $\mathrm{PCO}_{2}$ monitor that received input from a connection to the expiration hole of the mask worn by the participant. $\mathrm{PCO}_{2}$ levels were examined in the 30-s period immediately following termination of $\mathrm{CO}_{2}$ delivery, as research in our laboratory has shown this period captures the peak effects of $\mathrm{CO}_{2}$ on physiological, motor, and cognitive behavior.

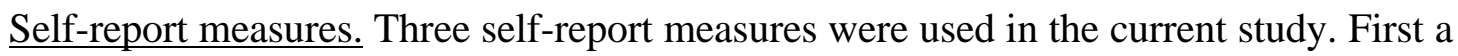
visual analog scale was used to measures preference between the predictable and unpredictable trials. For this comparison, the letters "T" and "N" were placed on opposite ends of a 100-mm horizontal line; participants were asked to draw a vertical line at some point across the horizontal line indicating predictability preference. To determine preference, the distance of the vertical line drawn from the center of the $100-\mathrm{mm}$ horizontal line was measured, with a maximum score of + $50 \mathrm{~mm}$ for predictable $\mathrm{CO}_{2}$ and $-50 \mathrm{~mm}$ for unpredictable $\mathrm{CO}_{2}$. Additionally, self-report of anxiety and unpleasantness were collected via questions provided on the computer monitor. First, participants rated the unpleasantness of the previous $\mathrm{CO}_{2}$ presentation ("how unpleasant was breathing the carbon dioxide just now?") on a likert scale ranging from 0 (not unpleasant) to 10 
(extremely unpleasant). Second, participants rated their current anxiety level ("what is your current anxiety level") on a likert scale from 0 (no anxiety) to 10 (extreme anxiety). Participants responded to the questions by typing in a number on the attached keyboard.

Screening. The ASI was used as a screening measure for participation. The ASI is a 16item self-report questionnaire that assesses fear of anxiety-related symptoms based on the belief that such sensations have negative consequences (e.g., physical illness). Respondents rate the degree to which they agree or disagree with each item on a 5-point Likert-type scale with anchors of 0 (very little) and 4 (very much). The ASI total score is derived by summing all responses, with total scores ranging from 0 to 64 . The ASI has sound psychometric properties (Peterson \& Reiss, 1992) and has been shown to predict anxious and panic responding in the laboratory and natural environment (Schmidt, Lerew, \& Jackson, 1997).

Procedure

Upon arrival, participants completed the consent form. After completing the consent form, participants were seated in the participant room and the c-pap mask was placed over their mouth and nose. Participants were then asked to remove any jewelry (e.g., a watch). After the experimenter left the room, participants sat quietly for a 5-min adaptation period in which baseline physiological responses were measured. The remainder of the experiment consisted of a 50-min experimental session, separated into 1-min trials, consisting of 2 phases.

Phase 1. The aim of Phase 1 was to provide participants with forced exposure to predictable and unpredictable $\mathrm{CO}_{2}$ presentations. Forced exposure was used in Phase 1 to increase the likelihood that choices in Phase 2 would more likely be based upon actual exposure to the 
experimental contingencies. Prior to the start of Phase 1, the experimenter entered the participant room and provided the following written instructions:

During this experiment, you will breathe regular room air through a mask. Occasionally, the concentration of carbon dioxide through the breathing mask will be increased. For many individuals, $\mathrm{CO}_{2}$ produces a variety of temporary effects including mild chest pain, racing heart, shortness of breath, faintness, dizziness, sweaty palms, increased breathing and blurred vision. This part of the experiment is separated into several experimental periods. At the start of each period, either the letter "T" or "N" will appear on the computer screen. When you see this letter, type it into the attached keyboard. When the letter $\mathrm{T}$ is typed, a tone will come from the computer if carbon dioxide is scheduled to be presented in that period. Furthermore, the sound of the tone will change 5 seconds before the $\mathrm{CO}_{2}$ occurs. If $\mathrm{CO}_{2}$ is not scheduled to occur in that period, no tone will be presented. In contrast, if the letter " $\mathrm{N}$ " is pressed, a tone will not be provided even if $\mathrm{CO}_{2}$ is scheduled in the upcoming period. Thus, when $\mathrm{CO}_{2}$ is presented, it always will be proceeded by a tone when " $\mathrm{T}$ " is typed and never proceeded by a tone when " $\mathrm{N}$ " is typed. There is no time limit for typing a letter once it appears on the screen, but long delays will increase the duration of your participation. Following each presentation of $\mathrm{CO}_{2}$, several questions will be presented on the computer screen. Please answer these questions using the attached keyboard.

Phase 1 lasted 30 min, which included 24 1-min trials and 6 1-min rest periods (each

following a $\mathrm{CO}_{2}$ presentation). Within these 24 trials, 6 included a $\mathrm{CO}_{2}$ presentation and 18 did not. Trials without $\mathrm{CO}_{2}$ were used to enhance the overall unpredictability of when $\mathrm{CO}_{2}$ presentations would occur. The duration of each $\mathrm{CO}_{2}$ presentation was $20 \mathrm{~s}$.

In Phase 1, each trial began with the appearance of either the letter " $T$ " or " $N$ " on the computer screen. This letter appeared in the center of the screen in 12 point font. The letter "T" signified that the $\mathrm{CO}_{2}$ would be signaled by a tone from the computer, thus making the presentation predictable. In contrast, the letter "N" signified that the $\mathrm{CO}_{2}$ would not be signaled 
by a tone from the computer, thus making the presentation unpredictable. The trial began once the letter on the screen was typed on the keyboard by the participant. The order of the first and subsequent presentations of " $\mathrm{T}$ " or "N" were determined by the computer in a semi-random fashion for each participant, with the constraint that the same letter could never appear three times in a row.

During a trial including a predictable $\mathrm{CO}_{2}$ administration, a $200 \mathrm{~Hz}$ tone was sounded at the start of the trial (i.e., first tone). Five s before the presentation commenced, the tone changed to $320 \mathrm{~Hz}$ and continued until the termination of the $\mathrm{CO}_{2}$ presentation (i.e., second tone). Thus, the initial tone signaled that $\mathrm{CO}_{2}$ would occur within that trial and the change in tone signaled exactly when the $\mathrm{CO}_{2}$ would occur. During a trial including an unpredictable $\mathrm{CO}_{2}$ administration, no warning tones were provided.

At the conclusion of each $\mathrm{CO}_{2}$ presentation and the following rest period, yet prior to the start of the next trial, self-reported unpleasantness and anxiety were assessed. At the conclusion of Phase 1, participants completed the visual analog scale to assess self-reported preference for the predictable/unpredictable $\mathrm{CO}_{2}$ administrations. Following completion of the self-report measures at the conclusion of Phase 1, participants were given a 5 min. break.

Phase 2. The aim of Phase 2 was to evaluate predictability preference for $\mathrm{CO}_{2}$ presentations. After the 5-min. break, the experimenter initiated Phase 2 by providing the following written instructions:

In the remainder of the experiment, the letters " $\mathrm{T}$ " and " $\mathrm{N}$ " will appear together on the computer screen and you may pick the one you prefer. Once you see this pair of letters, type the preferred letter on the provided keyboard. Otherwise, the remainder of the experiment is identical to what you have just completed. 
The Phase 2 procedure was identical to Phase 1 with two exceptions. First, to limit the participants overall exposure to $\mathrm{CO}_{2}$, fewer trials were used in Phase 2. Specifically, Phase 2 lasted 20 min, which included 16 1-min trials and 41 -min rest periods (each following a $\mathrm{CO}_{2}$ presentation). Within these 16 trials, 4 included a $\mathrm{CO}_{2}$ presentation and 12 did not. Second, the participant could choose whether a $\mathrm{CO}_{2}$ presentation would be predictable or unpredictable. To provide this choice, the letters " $\mathrm{T}$ " and "N" appeared together on the screen at the start of each trial. Each time the two letters appeared on the computer screen, the participant would type the preferred letter. Once the preferred letter was typed, the trial would begin and proceed as in Phase 1.

Unlike Phase 1, visual analog preference was not collected at the conclusion of Phase 2 to prevent the potentially confounding effect of an unequal number of predictable and unpredictable $\mathrm{CO}_{2}$ presentations.

Results

\section{Choice Responding}

The primary dependent measure was choice between predictable $\mathrm{CO}_{2}$ ("T") and unpredictable $\mathrm{CO}_{2}$ ("N") in Phase 2. To provide this choice score, the number of choices of the predictable $\mathrm{CO}_{2}$ alternative were summed such that scores could range from 18 for extreme choice of the predictable alternative to 0 for extreme choice of the unpredictable $\mathrm{CO}_{2}$ alternative.

Choice ratings were evaluated with a $2 \times$ (ASI: high, low) $2 \times$ (Gender: male, female)

ANOVA. There was no interaction of ASI and gender regarding choice alternatives. As shown in the left panel of Figure 1, a main effect was evident for anxiety sensitivity, with high ASI participants $(\underline{\mathrm{M}}=13.15, \mathrm{SE}=.84)$ choosing predictable $\mathrm{CO}_{2}$ administrations more often than 
their low ASI counterparts $(\underline{\mathrm{M}}=9.8, \mathrm{SE}=0.97[\mathrm{~F}(1,39)=8.27, \mathrm{p}=.007])$. In a related way

(right panel of Figure 1), a main effect was evident for gender, with females $(\underline{\mathrm{M}}=13.35, \mathrm{SE}=$ $0.9)$ choosing predictable $\mathrm{CO}_{2}$ more than males $(\underline{\mathrm{M}}=9.6, \mathrm{SE}=0.88[\underline{\mathrm{F}}(1,39)=10.4, \mathrm{p}=.003])$.

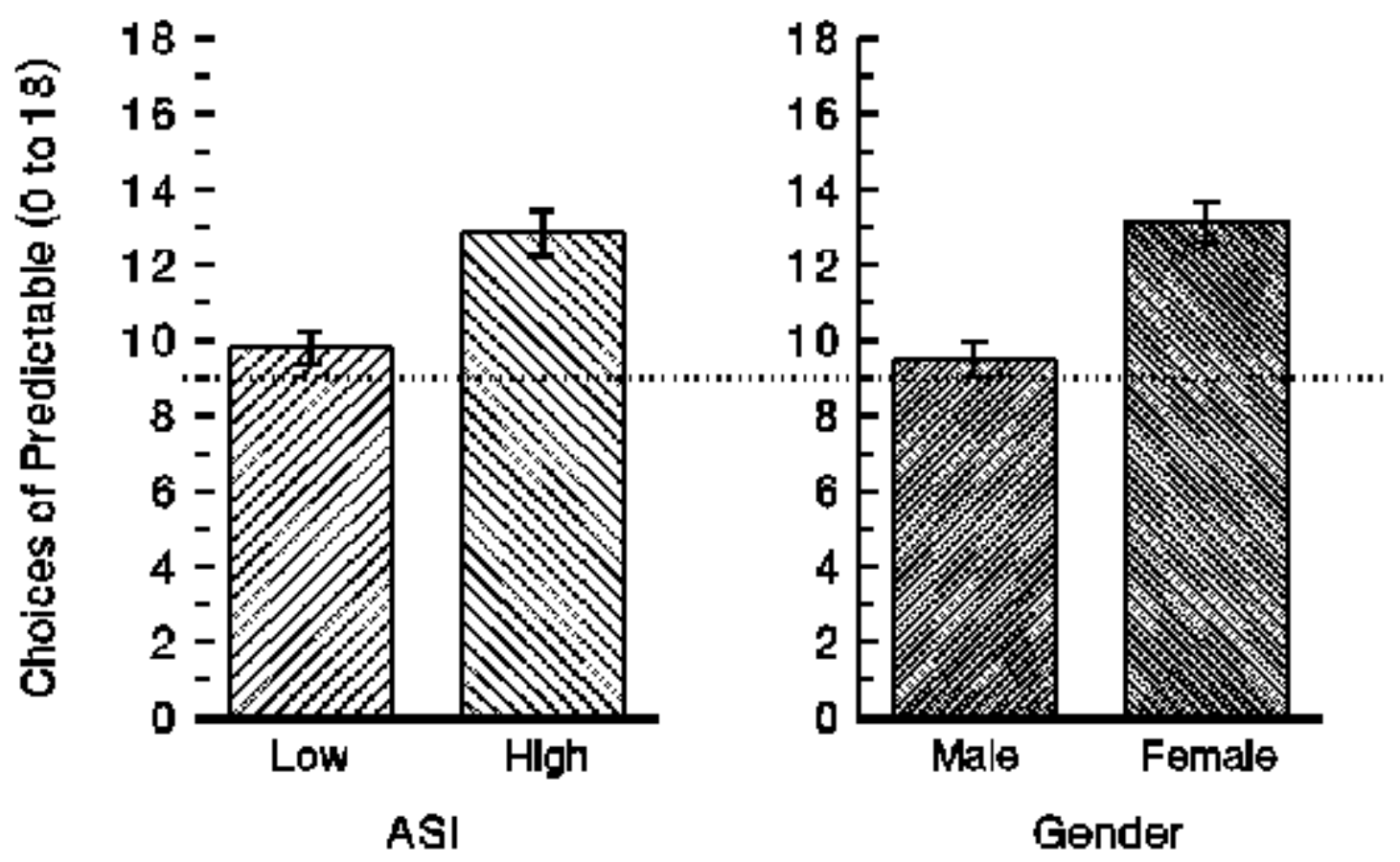

Figure 1. Number of choices of the predictable alternative across ASI and gender.

Given that the high ASI females ( $\underline{X}=38.8)$ had higher ASI scores than the high ASI males $(\underline{X}=30.8)$, it could be suggested that the gender effect actually may have been due to higher female ASI scores. To address this issue, a one-way Analysis of Covariance (ANCOVA) 
was conducted with gender as a between subjects factor and ASI score as a covariate. After controlling for the effects of differing preexperimental ASI scores, females again were shown to choose predictable $\mathrm{CO}_{2}$ more frequently than males $(\underline{\mathrm{F}}(1,39)=7.6, \underline{\mathrm{p}}=.009)$. This result suggests that gender affected preference, at least somewhat independent of ASI score.

Although the reported main effects suggest within factor differences in choice scores, these results do not establish if the choice scores for the participants as a whole, or any particular group of participants (e.g., high ASI females) differed from a score of 9 (i.e., indifference). A choice score of 9 was used to signify indifference because it comprised an equal number of choices for the predictable and unpredictable alternative. To provide a general assessment of choice regarding predictable and unpredictable aversive events, we employed a one-sample t-test to compare mean choice scores across all participants to a choice score of 9 . This analysis indicated that choice of predictable $\mathrm{CO}_{2}(\underline{\mathrm{M}}=11.48, \mathrm{SE}=0.69)$ was greater than the indifference value of $9(\underline{t}(39)=3.59, \underline{p}=.001)$.

To more closely examine this effect across groups, a one-tailed one-sample t-test was used to determine if the mean choice score for each group was different than the indifference value in the direction of predictability. As shown in Figure 2, choice scores for High ASI females ( $\underline{\mathrm{t}}(9)=$ 6.95, $\mathrm{p}<.001)$, High ASI males $(\underline{\mathrm{t}}(9)=1.9, \underline{\mathrm{p}}=.046)$, and Low ASI females $(\underline{\mathrm{t}}(9)=1.91, \underline{\mathrm{p}}=$ $.044)$ all were greater than 9. In contrast, choice scores for low ASI males did not differ from 9. To further investigate the groups preferring predictability, a one-tailed independent sample t-test found that choice scores for High ASI females were greater than that for both High ASI males $(\underline{\mathrm{t}}(18)=2.3, \underline{\mathrm{p}}=.017)$ and Low ASI females $(\underline{\mathrm{t}}(18)=1.83, \underline{\mathrm{p}}=.042)$. Choice scores for High ASI males and Low ASI females did not differ. 


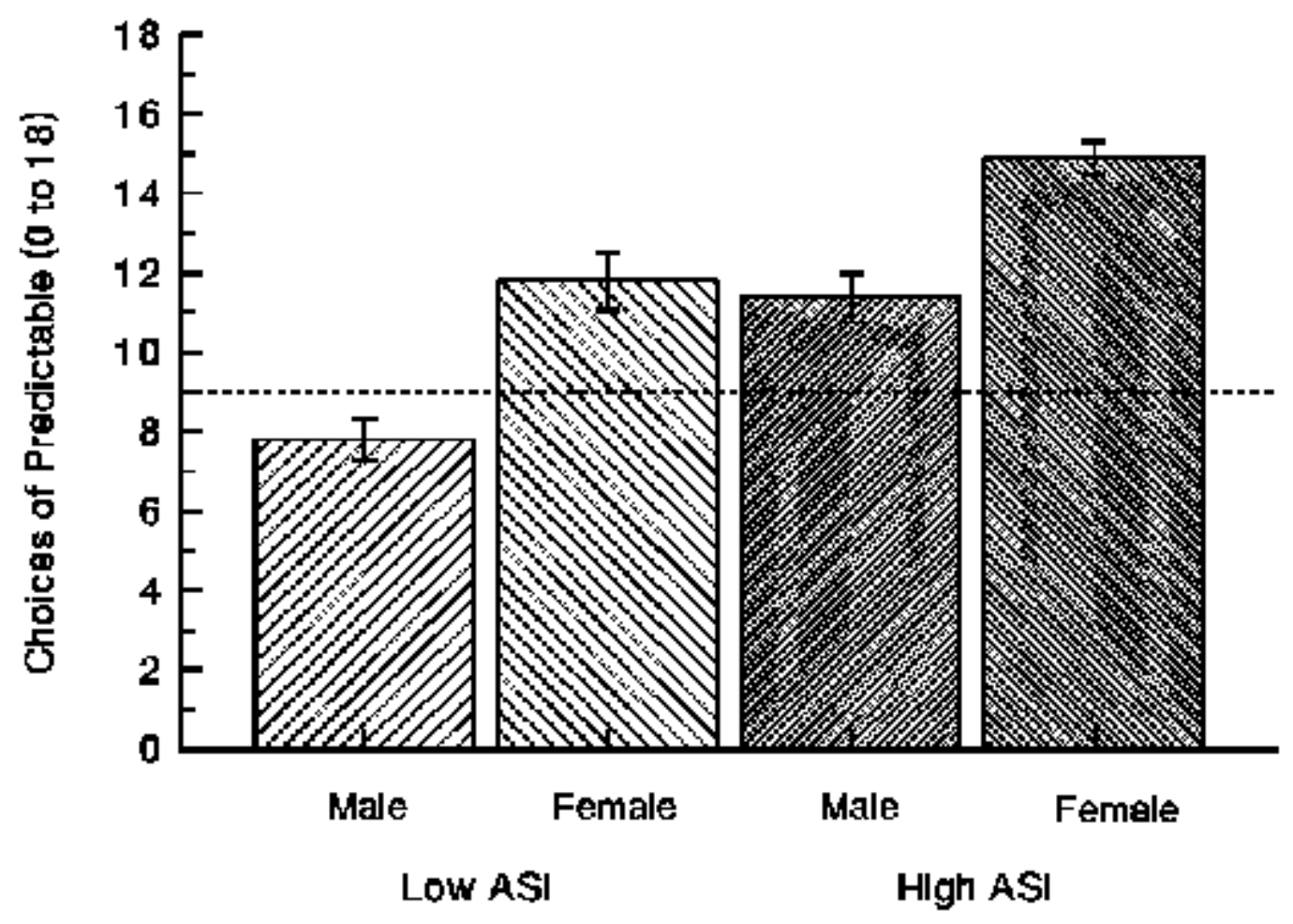

Figure 2. Number of choices of the predictable alternative across low ASI males, low ASI females, high ASI males, and high ASI females. 
$\underline{\text { Visual Analog Scale }}$

Phase 1 preference responding on the visual analog scale was examined with a $2 \times$ (ASI: high, low) 2 x (Gender: male, female) ANOVA. There was no interaction for anxiety sensitivity and gender. Similar to choice, the left panel of Figure 3 showed that preference for the predictable alternative was higher for high ASI participants $(\underline{\mathrm{M}}=16.73, \mathrm{SE}=5.86)$ compared to low ASI participants $(\underline{\mathrm{M}}=-1.26, \mathrm{SE}=4.09 ; \underline{\mathrm{F}}(1,39)=6.19, \underline{\mathrm{p}}=.018)$. Although the right panel of Figure 3 showed that the preference for the predictable $\mathrm{CO}_{2}$ alternative was higher for females $(\underline{\mathrm{M}}=$ $11.3, \mathrm{SE}=5.78)$ than for males $(\underline{\mathrm{M}}=4.17, \mathrm{SE}=4.98)$, this difference was not statistically significant. 

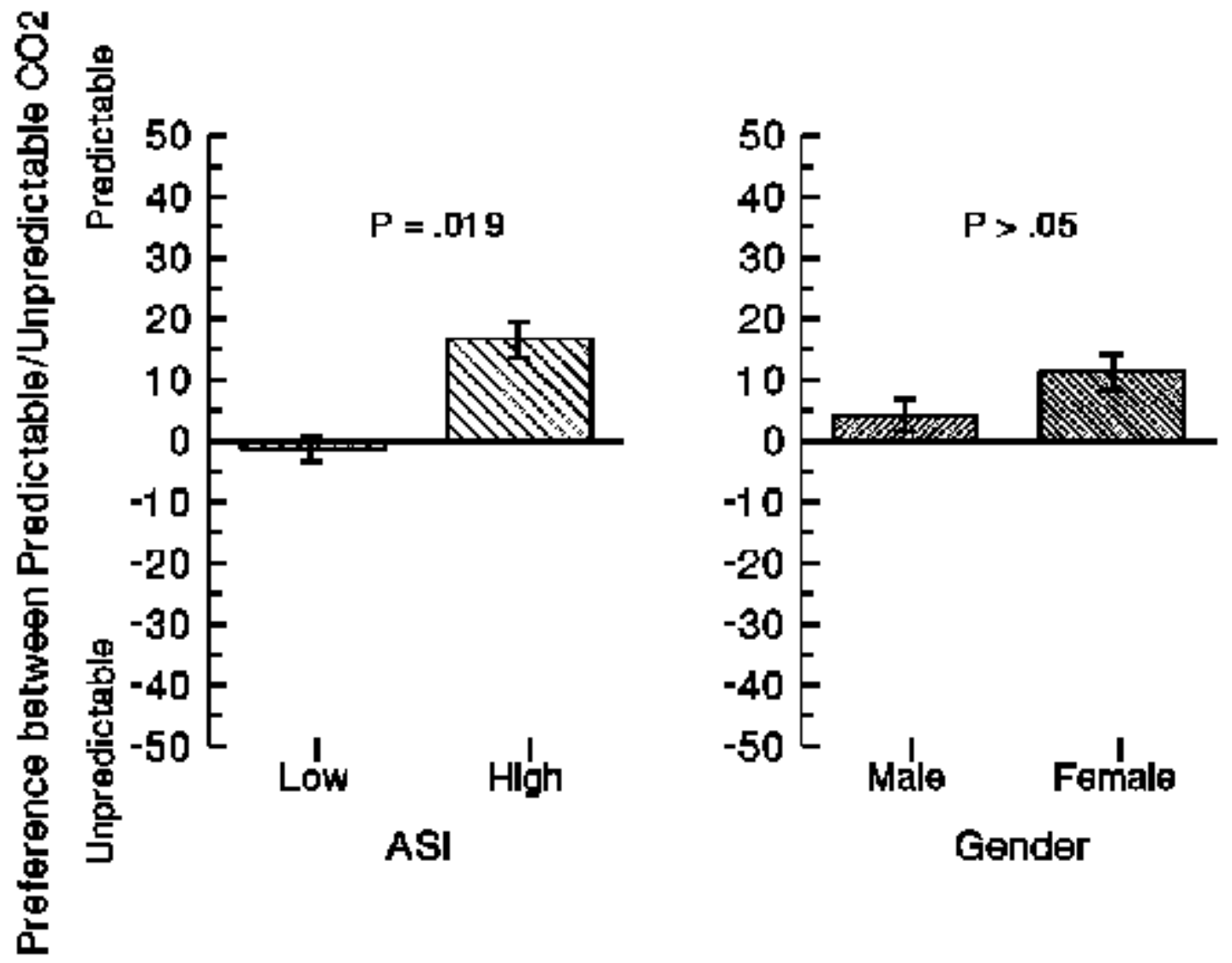

Figure 3. VAS score comparing preference between predictable and unpredictable trials across ASI and gender.

As with choice responding, we assessed for general patterns of responding across all participants with a one-sample t-test. Preference for the predictable $\mathrm{CO}_{2}$ alternative $(\underline{\mathrm{M}}=7.75$, $\mathrm{SE}=3.75$ ) was rated as greater than 0 (i.e., the indifference value; $\underline{\mathrm{t}}(39)=2.03, \mathrm{p}<.05$ ). This result, however, may have been primarily due to high ASI females. As shown in Figure 4, although the preference scores for the high ASI females, high ASI males, and low ASI females were greater than 0 , this difference from 0 only was statistically significant for high ASI females 
$(\mathrm{t}(9)=2.86, \mathrm{p}=.009)$. Although the mean preference score for low males was in the direction of unpredictability, this score was not significantly different than 0 . $(\mathrm{t}(9)=2.86, \mathrm{p}=.009)$.

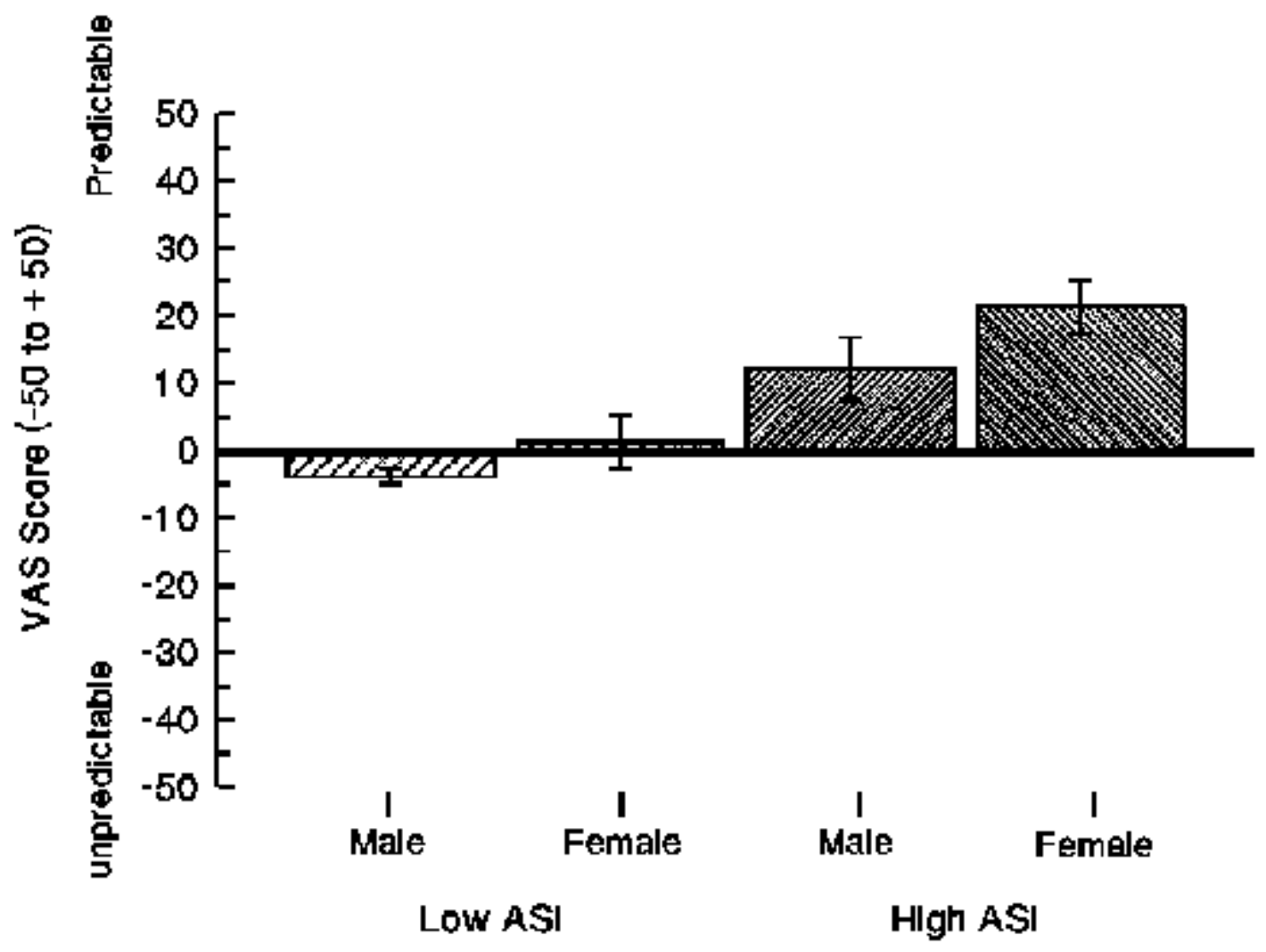

Figure 4. VAS score comparing preference between predictable and unpredictable trials across low ASI males, low ASI females, high ASI males, and high ASI females.

In general, preference of predictable $\mathrm{CO}_{2}$ was similar to the distribution of choice. Suggesting synchrony across overt-motor and self-report responses, a moderate to high 
correlation $(\underline{r}=.6, \underline{p}<.01)$ was found between preference scores as indexed by the visual analog scale at the conclusion of Phase 1 and the distribution of choices in Phase 2.

\section{Self-Reported Unpleasantness}

Self-reported unpleasantness was examined with a 2 x (ASI: high, low) 2 x (Gender: male, female) $2 \times$ (Predictability type: predictable $\mathrm{CO}_{2}$, unpredictable $\left.\mathrm{CO}_{2}\right) \times 10$ (trials) ANOVA with repeated measures on trials. No interactions were evident. There was a main effect for anxiety sensitivity, with self-reported unpleasantness being rated higher by high ASI participants $(\underline{\mathrm{M}}=$ $5.43, \mathrm{SE}=0.46)$ than low ASI participants $(\underline{\mathrm{M}}=3.0, \mathrm{SE}=0.46[\underline{\mathrm{F}}(1,39)=12.53, \underline{\mathrm{p}}=.001])$. In a similar way, unpleasantness was rated higher by females $(\underline{\mathrm{M}}=5.03, \mathrm{SE}=0.52)$ than males $(\underline{\mathrm{M}}=$ $3.4, \mathrm{SE}=0.58[\underline{\mathrm{F}}(1,39)=5.63, \mathrm{p}=.023])$.

\section{Self-Reported Anxiety}

Self-reported anxiety was examined with a 2 x (ASI: high, low) 2 x (Gender: male, female) 2 x (Predictability type: predictable $\mathrm{CO}_{2}$, unpredictable $\mathrm{CO}_{2}$ ) x 10 (trials) ANOVA, with repeated measures on trials. There were no interactions. There was a main effect for anxiety sensitivity, with greater self-reported anxiety being reported by high ASI participants $(\underline{\mathrm{M}}=5.08$, $\mathrm{SE}=0.43)$ relative to low ASI participants $(\underline{\mathrm{M}}=2.28, \mathrm{SE}=0.54[\underline{\mathrm{F}}(1,39)=16.83, \underline{\mathrm{p}}<.001])$. Self-reported anxiety was rated higher by females $(\underline{M}=4.13, S E=0.57)$ than males $(\underline{M}=3.23$, $\mathrm{SE}=0.58)$, but this difference was not statistically significant.

\section{Expired $\mathrm{CO}_{2} \underline{\text { levels }\left(\mathrm{PCO}_{2}\right)}$}

To examine differences in $\mathrm{CO}_{2}$ consumed between groups individuals, $\mathrm{PCO}_{2}$ was evaluated during the 30-s period immediately following each $\mathrm{CO}_{2}$ presentation using a 2 x (ASI: high, low) $2 \times$ (Gender: male, female) $2 \times$ (Predictability type: predictable $\mathrm{CO}_{2}$, unpredictable 
$\left.\mathrm{CO}_{2}\right) \times 10$ (trials) ANOVA, with repeated measures on trials. There were no interactions. A main effect of ASI was found, with $\mathrm{PCO}_{2}$ levels for low ASI participants $(\underline{\mathrm{M}}=52.6, \mathrm{SE}=2.37)$ being higher than for their high ASI participants $(\underline{\mathrm{M}}=45.2, \mathrm{SE}=2.13(\underline{\mathrm{F}}(1,39)=5.3, \mathrm{p}=.03)$. No difference in $\mathrm{PCO}_{2}$ levels across groups was evidenced in the absence of $\mathrm{CO}_{2}$ presentations. $\underline{\text { Skin Conductance Levels }}$

Although preexperimental skin conductance levels were assessed, these levels were considerably higher than during the $\mathrm{CO}_{2}$ free periods in the actual sessions, which may have been a result of preexperimental anticipatory anxiety. Thus, the average of the first five seconds of all trials in which a $\mathrm{CO}_{2}$ delivery was not scheduled to occur (i.e., $\mathrm{CO}_{2}$ free trials) was used as a baseline-like comparison period. Regarding skin conductance levels during (a) during $\mathrm{CO}_{2}$ free trials or (b) $\mathrm{CO}_{2}$ trials including the actual $\mathrm{CO}_{2}$ presentations or the 30 -s rest period immediately following the $\mathrm{CO}_{2}$ presentation, there were no interactions or main effects of ASI, gender, and predictability type (predictable or unpredictable $\mathrm{CO}_{2}$ ).

Despite the absence of differential effects, we observed several general effects of $\mathrm{CO}_{2}$. First, skin conductance levels increased from an average level of $0.71(\mathrm{SE}=0.06)$ during $\mathrm{CO}_{2}$ free trials to $1.39(\mathrm{SE}=0.26)$ during the first warning tone $(\mathrm{t}(39)=2.88, \mathrm{p}=.008)$ and $1.23(\mathrm{SE}=$ $0.21)$ during the second warning tone $(\underline{\mathrm{t}}(39)=2.67, \mathrm{p}=.013)$ prior to predictable $\mathrm{CO}_{2}$ administrations. Skin conductance levels also increased from $\mathrm{CO}_{2}$ free trials to 1.18 during the 20$\mathrm{s} \mathrm{CO}_{2}$ durations, collapsed across predictable and unpredictable administrations $(\underline{\mathrm{t}}(39)=3.99, \mathrm{p}=$ $.001)$. 


\section{Discussion}

When given the choice between predictable and unpredictable administrations of $20 \%$ $\mathrm{CO}_{2}$, participants opted for predictability. Further examination, however, shows that this effect was strongest for females compared to males as well as high anxiety sensitive participants compared to their low anxious counterparts. As indexed by choice responding, high anxious females showed the greatest for predictability, high anxious males and low anxious females showed moderate preference for predictability, and low anxious males were indifferent. Similar results were found using the VAS to index preference between trials in which $\mathrm{CO}_{2}$ was predictable and unpredictable.

Regarding self-report and physiological responses, predictable $\mathrm{CO}_{2}$ presentations compared to unpredictable $\mathrm{CO}_{2}$ presentations were (a) rated as equally unpleasant and anxiety provoking and (b) resulted in similar changes in skin conductance levels. These results do not indicate an effect of predictability, but self-report and physiological measures often have been shown to be somewhat insensitive in studies showing preference for information regarding aversive medical procedures (see Ludwick-Rosenthal \& Neufeld, 1988 for a review).

Although differential effects of predictable and unpredictable $\mathrm{CO}_{2}$ were not reported, $\mathrm{CO}_{2}$ did have a more pronounced effect on females compared to males (unpleasantness) and on high ASI individuals compared to low ASI individuals (unpleasantness and anxiety).

\section{General Effects}

The present results provide preliminary experimental support for the use of prediction testing and other strategies to enhance an individual's ability to identify cues for panic attacks in the treatment of PD. Nevertheless, the factors underlying the benefits of predictability remain 
somewhat unclear. Although both the safety-signal (Seligman, 1968) and the preparatory response hypothesis (Perkins, 1955) imply preference for predictable $\mathrm{CO}_{2}$, several aspects of the results are not consistent with the latter hypothesis. First, $\mathrm{PCO}_{2}$ levels suggest that participants did not breathe less during predictable $\mathrm{CO}_{2}$ presentations than during unpredictable presentations. Although other types of coping strategies (e.g., distraction) may have been employed, the differences between predictable and unpredictable $\mathrm{CO}_{2}$ can not be ascribed to breath holding, an obvious preparatory-response for predictable $\mathrm{CO}_{2}$ presentations.

Second, when participants rated the unpleasant and anxiety-provoking qualities of the $\mathrm{CO}_{2}$, immediately after each presentation, no difference was found between predictable and unpredictable $\mathrm{CO}_{2}$. In contrast, differences were found when participants indicated their preference between the predictable and unpredictable trials at the conclusion of Phase 1 . Thus, a focus on the actual aversive stimulus found no difference between predictable and unpredictable $\mathrm{CO}_{2}$ presentations, whereas a focus on the entire context (i.e., considering both trials in which $\mathrm{CO}_{2}$ was present and absent), did reveal preference for predictability. Although fundamental differences between the scale used to rate unpleasantness and anxiety compared to the VAS scale used to compare preference might account for the observed differences, the benefits of predictability may extend beyond simply just preparing for the presentation of the aversive stimulus.

In addition to the above points, the potential difficulty of controlling panic-related symptoms, even when the onset is predicted, suggest that the safety-signal hypothesis may be more relevant than the preparatory-response hypothesis to the benefits of predictability in the natural environment. Specifically, applying the safety-signal hypothesis to PD takes the focus 
away from actual panic attacks and instead focuses on the absence of panic related stimuli and the safety that can be ascribed to the absence of those stimuli. Thus, the safety-signal hypothesis may be most relevant when an individual is not experiencing a panic attack. Consequently, individuals with PD might be taught to identify stimuli associated with panic attacks to more clearly identify periods of safety and thereby reduce worry regarding future attacks.

\section{$\underline{\text { Anxiety Sensitivity and Gender Effects }}$}

Although the present results provide general support for preference of predictability, the ASI and gender effects provide more detailed insight into the potential processes underlying this preference. As a possible explanation of the ASI effect, individuals in the high ASI group reported the $\mathrm{CO}_{2}$ (collapsed across predictable and unpredictable administrations) to be more unpleasant and anxiety provoking than individuals in the low ASI group (cf. Eke \& McNally, 1996). Consequently, the increased effects of $\mathrm{CO}_{2}$ for the high ASI individuals may have been related to the preference for predictable $\mathrm{CO}_{2}$, whereas the limited effects of the $\mathrm{CO}_{2}$ for the low ASI individuals may have been related to the greater level of indifference regarding predictability. Thus, a higher concentration and/or longer duration of $\mathrm{CO}_{2}$ might produce greater preference for predictability for low ASI individuals in general and specifically for low ASI males whose ratings of unpleasantness and anxiety were considerably lower than that for the other groups.

Higher ASI scores in the natural environment and a greater number of reported anxietyrelated concerns fears for females compared to males may serve as a potential explanation of the gender effect (Kirkpatrick \& Berg, 1982; Stewart, Taylor, \& Baker, 1997). Because females in this study had higher ASI scores than males, one could suspect that the gender effect was due to differences in anxiety sensitivity. A covariate analysis, however, found that a strong gender effect 
also was evidenced after controlling for ASI score, suggesting that gender effects are at least at some level orthogonal from ASI effects.

As an alternative hypothesis, it has been suggested that females engage in information seeking regarding future unpleasant events more than males (Blanchard et al. 1995). Supporting this hypothesis, females frequently chose predictability despite the fact that the predictable $\mathrm{CO}_{2}$ remained both aversive and anxiety provoking. Thus, these results suggest that information regarding both danger and safety may have benefits to the individual, independent of the reported aversiveness of the unpleasant stimulus.

\section{$\underline{\text { Potential limitations }}$}

One concern regarding the present results is that predictability might have been beneficial because participants were taking a deep breath during the warning signal and then holding their breath during the following $\mathrm{CO}_{2}$ presentation; a strategy that cannot be employed in response to unpredictable administrations. To address this issue, the present study monitored $\mathrm{PCO}_{2}$ levels during $\mathrm{CO}_{2}$ presentations. As $\mathrm{PCO}_{2}$ levels showed similar $\mathrm{CO}_{2}$ levels during predictable and unpredictable administrations, the benefits of predictability can not be tied to a decrease in $\mathrm{CO}_{2}$ inspired during predictable administrations. There is evidence, however, that $\mathrm{PCO}_{2}$ levels were lower for high ASI individuals compared to low ASI across both predictable and unpredictable administrations. This result suggests that despite breathing in less gas (i.e., passive avoidance), high ASI individuals engaged in more extreme choice of and preference for predictable $\mathrm{CO}_{2}$, and reported greater anxiety and unpleasantness of $\mathrm{CO}_{2}$ in general. Interestingly, such preparatory responses had little positive effect, suggesting that aversiveness is not necessarily correlated with absolute $\mathrm{PCO}_{2}$ levels. 
Despite the validity check provided by the $\mathrm{PCO}_{2}$ monitor, potential limitations remain when using a preset duration, and not $\mathrm{PCO}_{2}$ levels, to determine the duration of each $\mathrm{CO}_{2}$ presentation. Although $\mathrm{PCO}_{2}$ levels across predictable and unpredictable administrations did not differ in the current study, the potential for such differences in future studies is of concern. Further, little is known regarding the factors determining the effects of $\mathrm{CO}_{2}$ across different individuals. That is, are factors such as gender, weight, or physical fitness important in determining the effects of $\mathrm{CO}_{2}$, and should they be used to determine an individualized duration presentation as opposed to a uniform duration across all participants? For example, the fact that females reported the $\mathrm{CO}_{2}$ as more unpleasant than the males may reflect real differences in the actual effects of $\mathrm{CO}_{2}$ across gender, or instead a greater propensity in females to report psychological and physical symptoms than males (Cleary, Burns, \& Nycz, 1990; Corney, 1990; Knight \& Elfenbein, 1996; Wolitski, Bensley, Corby, Fishbein, \& Galavotti, 1997). Although such questions are valid and deserve empirical investigation, the skin conductance effects in the present study suggest that the $\mathrm{CO}_{2}$ methodology at least was effective in producing an anxious state in most participants.

Conclusions

A large body of animal research has suggested the benefits of predictability of aversive events (Badia, Harsh, \& Abbott; Seligman, 1968; Weiss, 1968, 1970). Despite the absence of clear results with humans, the concept of predictability has been integrated into the etiology and treatment of clinical anxiety, including PD. Regarding this integration, our results support the continued attention focused on the role of predictability for anxiety-related responding in PD and 
related nonclinical populations, while highlighting the importance of attending to individual difference variables such as anxiety sensitivity and gender.

The present results show preference for predictability, but questions as to why this preference exists are more difficult to answer. Our results appear to favor the safety-signal hypothesis, but it remains possible that both safety signals and the opportunity to prepare for an aversive event may mediate preference for predictability (Fanselow, 1980). As the purpose of the present experiment was not to provide a direct test of either, the exact mechanisms underlying preference for predictability of panic attacks needs to be examined in future research. 


\section{References}

Armfield, J. M., \& Mattiske, J. K. (1996). Vulnerability representation: the role of perceived dangerousness, uncontrollability, unpredictability and disgustingness in spider fear. Behaviour Research and Therapy, 34, 899-909.

Averill, J. R., \& Rosenn, M. (1972). Vigilant and nonvigilant coping strategies and psychophysiological stress reactions during the anticipation of an electric shock. Journal of Personality and Social Psychology, 23, 128-141.

Badia, P., Harsh, J., \& Abbott, B. (1979). Choosing between predictable and unpredictable shock conditions: Data and theory. Psychological Bulletin, 86, 1107-1131.

Badia, P., Harsh, J., Coker, C. C., \& Abbott, B. (1976). Choice and the dependability of stimuli that predict shock and safety. Journal of the Experimental Analysis of Behavior, 26, 95111.

Badia, P., McBane, B., Suter, S., \& Lewis, P. (1966). Preference behavior in an immediate versus variably delayed shock situation with and without a warning signal. Journal of Experimental Psychology, 72, 847-852.

Barlow, D. H. (1988). Anxiety and its disorders. New York: Guilford.

Barlow, D. H., Chorpita, B., F., \& Turovsky, J. (1996). Fear, panic, anxiety, and disorders of emotion. In D. Hope (Ed.) Nebraska symposium on motivation (pp. 251-328). Lincoln: University of Nebraska Press.

Barlow, D. H, \& Craske, M. G. (1994). Mastery of your anxiety and panic-II. Albany, New York: Graywind.4 
Beck, J. G., Shipherd, J. C., \& Zebb, B. J. (1996). Fearful responding to repeated $\mathrm{CO}_{2}$ inhalation: A preliminary investigation. Behaviour Research and Therapy, 34, 609-620.

Blanchard, D.C., Griebel, G., and Blanchard, R.J. (1995) Gender bias in preclinical psychopharmacology: Male models for (predominantly) female disorders. Journal of Psychopharmacology, 9, 79-82.

Bowers, K. S. (1971). The effects of UCS temporal uncertainty on heart rate and pain. Psychophysiology, 8, 382-389.

Corney, R. H. (1990). Sex differences in general practice attendance and help seeking for minor illness. Journal of Psychosomatic Research, 34, 525-34.

Craske, M. G., Glover, D., \& De Cola, J. (1995). Predicted versus unpredicted panic attacks: Acute versus general distress. Journal of Abnormal Psychology, 104, 214-223.

Cleary, P.D., Burns, B. J., \& Nycz, G. R. (1990). The identification of psychiatric illness by primary care physicians: the effect of patient gender. Journal of General Internal Medicine, 5 , 355-360.

Eifert, G. H., Schulte, D., Zvolensky, M. J., Lejuez, C. W., \& Lau, A. W. (1998). Manualized behavior therapy: Merits and challenges. Behavior Therapy, 28, 499-509.

Eke, M., \& McNally, R. J. (1996). Anxiety sensitivity, suffocation fear, trait anxiety, and breath-holding duration as predictors of response to carbon dioxide challenge. Behaviour Research and Therapy, 304, 603-607.

Estes, W. K., \& Skinner, B. F. (1941). Some quantitative properties of anxiety. Journal of Experimental Psychology, 29, 390-400. 
Fanselow, M. S. (1980). Signaled shock-free periods and preference for signaled shock. Journal of Experimental Psychology: Animal Behavior Processes, 6, 65-80.

First, M. B., Spitzer, R. L., Gibbon, M., \& Williams, J. B. W. (1995). Structured clinical interview for DSM-IV Axis I disorders. Biometrics Research Division, New York State Psychiatric Institute, New York: New York.

Foa, E., B., Zinbarg, R., \& Rothbaum, B. O. (1992). Uncontrollability and unpredictability in post-traumatic stress: An animal model. Psychological Bulletin, 112, 218-238. Forsyth, J. P., \& Eifert, G. H. (1998). Intensity of systemic alarms in content-specific fear conditioning: Comparing 20\% versus 13\% CO2-enriched air as a UCS. Journal of Abnormal Psychology, 107, 291-304.

Furedy, J. J., \& Chan, R. M. (1971). Failures of information to reduce rated aversiveness of unmodifiable shock. Australian Journal of Psychology, 23, 85-94.

Furedy, J. J., \& Doob, A. N. (1971a). Autonomic responses and verbal reports in further tests of the preparatory-adaptive-response interpretation of reinforcement. Journal of Experimental Psychology, 89, 258-264.

Furedy, J. J., \& Doob, A. N. (1971b). Classical aversive conditioning of human digital volume-pulse change and tests of the preparatory-adaptive response interpretation of reinforcement. Journal of Experimental Psychology, 89, 403-407.

Furedy, J. J., \& Doob, A. N. (1972). Signaling unmodifiable shocks: Limits on human informational cognitive control. Journal of Personality and Social Psychology, 21, 111-115.

Furedy, J. J., \& Klajner, F. (1972). Unconfounded autonomic indexes of the aversiveness of signaled and unsignaled shock. Journal of Experimental Psychology, 92, 313-318. 
Grusec, T., \& Grusec, J. E. (1971). Information seeking about uncertain but unavoidable outcomes: Effects of probability, valence, and intervening activity. Developmental Psychology, 5 , 177.

Janis, I. L. (1958). Psychological stress: Psychoanalytic and behavioral studies of surgical patients. New York: Wiley.

Jones, A., Bentler, P. M., \& Petry, G. (1966). The reduction of uncertainty concerning future pain. Journal of Abnormal Psychology, 71, 87-94.

Klein, D. F., \& Klein, H. M. (1989). The substantive effect of variations in panic measurement and agoraphobia definition. Journal of Anxiety Disorders, 3, 45-56.

Knight, K. H., \& Elfenbein, M. H. (1996). Relationship of death anxiety/fear to health seeking beliefs and behaviors. Death Studies, 20, 23-31.

Lejuez, C. W. (1997). Conditioned and unconditioned fear as a function of predictable and unpredictable administrations of carbon dioxide. Unpublished Master's Thesis.

Lejuez, C. W., Forsyth, J. P., \& Eifert, G. H. (1998). Devices and methods for administering carbon dioxide-enriched air in experimental and clinical settings. Journal of Behavior Therapy and Experimental Psychiatry, 29, 239-248.

Lejuez, C. W., O’Donell, J., Wirth, O., Zvolensky, M. J., \& Eifert, G. H. (1998). Avoidance of carbon dioxide-enriched air in humans. Journal of the Experimental Analysis of Behavior, 70, 79-86.

Lejuez, C. W., Zvolensky, M. J., Eifert, G. H., Sorrell, J. T., \& Shear, M. K. (1998). Preference among onset predictable, offset predictable, and unpredictable administrations of carbon dioxide-enriched air: A preliminary examination. Manuscript in progress. 
Lovibond, S. H. (1968). The aversiveness of uncertainty: An analysis in terms of activation and information theory. Australian Journal of Psychology, 20, 85-91.

Ludwick-Rosenthal, R., \& Neufeld, R. W. J. (1988). Stress management during noxious medical procedures: An evaluative review of outcome studies. Psychological Bulletin, 3, 326-342.

Maltzman, I., \& Wolff, C. (1970). Preference for immediate versus delayed noxious stimulation and the concomitant G. S. R. Journal of Experimental Psychology, 83, 76-79.

Margraf, J., Taylor, C. B., Ehlers, A., Roth, W., \& Agras, W. S. (1987). Panic attacks in the natural environment. Journal of Nervous and Mental Diseases, 175, 558-565.

McNally, R. (1994). Panic disorder: A critical analysis. New York: Guilford.

Miller, S. M., \& Grant, R. P. (1979). The blunting hypothesis: A view of predictability and human stress. In P. Sjoden, S. Bates, \& W. S. Dockens III (Eds.), Trends in behavior therapy (pp. 135-151). New York: Academic Press.

Mineka, S., \& Kilstrohm, J. (1977). Unpredictable and uncontrollable events: A new perspective on experimental neurosis. Journal of Abnormal Psychology, 87, 256-271.

Mineka, S., \& Zinbarg, R. (1996). Conditioning and ethological models of anxiety disorders: Stress in dynamic context anxiety models. In D. Hope (Ed.), Nebraska symposium on motivation (pp. 135-210). Lincoln: University of Nebraska Press.

Minor, T. R., Dess, N. K., \& Overmier, J. B. (1991). Inverting the traditional view of “learned helplessness.” In M. R. Denny (Ed.), Fear, avoidance, and phobias: A fundamental analysis (pp. 87-134). Hillsdale NJ: Erlbaum.

Perkins, C. C. (1955). The stimulus conditions which follow learned responses. Psychological Review, 62, 341-348. 
Perkins, C. C., Levis, D. F., \& Seyman, R. (1963). Preference for signal-shock versus shock-signal. Psychological Reports, 13, 735-738.

Peterson, R. A., \& Reiss, S. (1992). Anxiety Sensitivity Index Manual (2nd ed.). Worthington, OH: International Diagnostic Systems.

Rachman, S. J. (1990). Fear and courage (2nd ed.). New York: W. H. Freeman. Rachman, S., \& Loptaka, C. (1986). Do fears summate - III? Behaviour Research and Therapy, 24, 653-660.

Reiss, S., Peterson, R. A., Gursky, D. M., \& McNally, R. J. (1986). Anxiety sensitivity, anxiety frequency, and the prediction of fearfulness. Behaviour Research and Therapy, 24, 1-8.

Schmidt, N. B., Lerew, D. R., \& Jackson, R. J. (1997). The role of anxiety sensitivity in the pathogenesis of panic: Prospective evaluation of spontaneous panic attacks during acute stress. Journal of Abnormal Psychology, 106, 355-364.

Seligman, M. E. P. (1968). Chronic fear produced by unpredictable shock. Journal of Experimental Psychology, 72, 546-550.

Seligman, M. E. P., \& Meyer, B. (1970). Chronic fear and ulcers in rats as a function of the unpredictability of safety. Journal of Comparative and Physiological Psychology, 73, 202-207.

Stewart, S., H., Taylor, S., \& Baker, J. M. (1997). Gender differences in dimensions of anxiety sensitivity. Journal of Anxiety Disorders, 11, 179-200.

Street, L. L., Craske, M. G., \& Barlow, D. H. (1989). Sensations, cognitions, and the perception of cues associated with expected and unexpected panic attacks. Behaviour Research and Therapy, 27, 189-198. 
Weiss, J. M. (1968). Effects of coping responses on stress. Journal of Comparative and Physiological Psychology, 65, 251-260.

Weiss, J. M. (1970). Somatic effects of predictable and unpredictable shock. Psychosomatic Medicine, 32, 397-408.

Wolitski, R. J., Bensley, L., Corby, N. H., Fishbein, M., \& Galavotti, C. (1997). Sources of AIDS information among low-risk and at-risk populations in five U.S. cities. Journal of Community Health, 21, 293-310.

Zvolensky, M. J., Lejuez, C. W., \& Eifert, G. H. (1998). The role of offset control in anxious responding: An experimental test using repeated administrations of $20 \% \mathrm{CO}_{2}$-enriched air. Behavior Therapy, 29, 193-209.

Zvolensky, M. J., Eifert, G. H., Lejuez, C. W., \& McNeil, D. W. (in press). The effects of offset control over $20 \%$ carbon dioxide-enriched air on anxious responding. Journal of Abnormal Psychology. 


\section{CURRICULUM VITAE}

\section{Carl Wilbourne Lejuez}

April 15, 1999

\section{ERSONAL HISTORY}

Business Address: Department of Psychology

West Virginia University

Box 6040 Oglebay Hall

Morgantown, WV 26506-6040

Ph: (304) 293 - 2001 Ext: 834

E-mail: clejuez@wvu.edu

Home Address: 409-D Arch Street

Morgantown, WV 26505

Ph: (304) 296 - 0589

Birth Date and Place: $\quad$ October 12, 1971; Paterson, NJ

\section{EDUCATIONAL HISTORY}

1995-Present

1997

M.A.
Doctoral Program in Clinical Psychology

Department of Psychology

West Virginia University

Morgantown, WV 26506-6040

Emory University

Atlanta, GA 30322

Major: Psychology

\section{CURRENT PROFESSIONAL INTERESTS}

1. Integration of Basic and Applied Research

2. Laboratory Analogues of Conditioned Fear and Anxiety

3. Behavioral Treatments for Depression

4. Clinical Behavior Analysis and Therapy 


\title{
PROFESSIONAL ACTIVITIES
}

\section{EDITORIAL POSITIONS}

\author{
Ad-Hoc Reviewer Behavior Therapy (1996-1998) \\ Cognitive Therapy and Research $(1996,1998)$ \\ Journal of the Association for People with Severe Handicaps (1996) \\ Psychophysiology (1996) \\ Journal of Behavioral Medicine (1998)
}

\section{DEPARTMENTAL COMMITTEE MEMBERSHIP AND SERVICE}
1998-present
1997-1998
1996-present
1995-present
1995-1996

Graduate Training Committee

Faculty Evaluation Committee

Organized and facilitated a weekly clinical research meeting

Co-Editor of the West Virginia University Alumni Newsletter Committee

West Virginia University Alumni Fund Committee

\section{MEMBERSHIP IN PROFESSIONAL ASSOCIATIONS}

Student-Member

American Psychological Association (APA)

American Public Health Association (APHA)

Anxiety Disorders Association of America (ADAA)

Association for the Advancement of Behavior Therapy (AABT)

Association for Behavior Analysis (ABA)

Society for the Quantitative Analysis of Behavior (SQAB)

Southeastern Association for Behavior Analysis (SEABA)

\section{PUBLICATIONS}

\section{REFEREED ARTICLES}

Eifert, G. H., Forsyth, J. P., Zvolensky, M. J., \& Lejuez, C. W. (in press). Moving from the laboratory to the real world and back again: Increasing the relevance of laboratory examinations of anxiety. Behavior Therapy.

Heffner, M., Lejuez, C. W., \& Freeman, K. A. (in press). A behavioral formulation of HIVrelated anxiety: Etiology and treatment implications. the Behavior Therapist.

Lejuez, C. W., Hopko, D. H., LePage, J. P., Hopko, S. D., \& McNeil, D. W. (in press). A brief behavioral activation treatment for depression. Cognitive and Behavioral Practice. Accepted pending revisions. 
Lejuez, C. W., Zvolensky, M. J., \& Eifert, G. H. (in press). Using a single-subject design to assess the development of anxiety in humans. Journal of Behavior Therapy and Experimental Psychiatry.

Lejuez, C. W., Zvolensky, M. J., \& Eifert, G. H. (in press). The search for truth when assessing the development of anxiety in humans: A reply to Furedy. Journal of Behavior Therapy and Experimental Psychiatry.

Zvolensky, M. J., Eifert, G. H., Lejuez, C. W., \& McNeil, D. W. (in press). The effects of offset control over $20 \%$ carbon dioxide-enriched air on anxious responding. Journal of Abnormal Psychology.

Zvolensky, M. J., Lejuez, C. W., \& Eifert, G. H. (in press). The effects of prediction and control of aversive events on anxiety: An operational reformulation. Behavior Research and Therapy.

Zvolensky, M. J., Mullen, K. B., Lejuez, C. W., \& McNeil, D. W. (1999). Anxiety disorders support groups. the Behavior Therapist, 22, 50-52.

Lejuez, C. W., Forsyth, J. P., \& Eifert, G. H. (1998). Devices and methods for administering carbon dioxide-enriched air in experimental and clinical settings. Journal of Behavior Therapy and Experimental Psychiatry, 29, 239-248.

Lejuez, C. W., O'Donnell, J., Wirth, O., \& Zvolensky, M. J., \& Eifert, G. H. (1998). Avoidance of $20 \%$ carbon dioxide-enriched air with humans. Journal of the Experimental Analysis of Behavior, 70, 79-86.

Zvolensky, M. J., Lejuez, C. W., \& Eifert, G. H. (1998). The role of offset control in anxious responding: An experimental test using repeated administrations of $20 \% \mathrm{CO}_{2}$-enriched air. Behavior Therapy, 29, 193-209.

Eifert, G. H., Schulte, D., Zvolensky, M. J., Lejuez, C. W., \& Lau, A. W. (1997). Manualized behavior therapy: Merits and challenges. Behavior Therapy, 28, 499-509.

Forsyth, J. P., Lejuez, C. W., Hawkins, R. P., \& Eifert, G. H. (1996). Cognitive versus contextual causation: Different world views but perhaps not irreconcilable. Journal of Behavior Therapy and Experimental Psychiatry, 27, 369-376.

\section{BOOK CHAPTERS AND OTHER PUBLICATIONS}

Bouman, T., Eifert, G. H., \& Lejuez, C. W. (in press). Somatoform disorders. In T. Millon, P. H. Blaney, \& R. Davis (Eds.), Oxford textbook of psychopathology. Oxford: Oxford University Press. 
Eifert, G. H., \& Lejuez, C. W. (in press). Aversion Therapy. In A. E. Kazdin (Ed.), Encyclopedia of psychology. New York: American Psychological Association and Oxford University Press.

Eifert, G. H., Lejuez, C. W., \& Bouman, T. (1998). Somatoform disorders. In A. S. Bellack \& M. Hersen (Series Eds.) \& P. M. Salkovskis (Vol. Ed.), Comprehensive clinical psychology: Vol. 6 Adults: Clinical formulation and treatment (pp. 543-565). Oxford: Pergamon.

Lejuez, C. W., Schaal, D., \& O'Donnell, J. (1998). Behavior pharmacology and the treatment of substance abuse. In J. J. Plaud \& G. H. Eifert (Eds.), From behavior theory to behavior therapy (pp.116-135). Needham Heights, Ma: Allyn and Bacon.

Schaal, D. W., \& Lejuez, C. W. (1997). The behavioral treatment of substance abuse. West Virginia Journal of Psychological Research and Practice, 6, 57-68.

\section{CONFERENCE PRESENTATIONS 1999}

McNeil, D. W., \& Lejuez, C. W. (1999, March, Co-Chairs). Books on social anxiety and phobia: The authors and editors speak. Symposium conducted at the 19th annual meeting of the Anxiety Disorders Association of America, San Diego, Ca.

Lejuez, C. W., Zvolensky, M. J., Sorrell, J. T., Heffner, M. P., Eifert, G. H., \& Shear, M. K. (1999, March). The interaction of prediction and control: Implications for the development and maintenance of anxiety. Paper presented at the 19th annual meeting of the Anxiety Disorders Association of America, San Diego, Ca.

\section{8}

Lejuez, C. W. (1998, November, Chair). A behavioral analysis of hypochondriasis: Theoretical, research, and treatment implications. Symposium conducted at the 32nd annual meeting of the Association for the Advancement of Behavior Therapy, Washington, DC.

Lejuez, C. W., \& Chase, P. N. (1998, November). Choice and cooperation: A quantitative formulation. In P. N. Chase and A. Rabalais (Co-Chairs), Behavior analytic interpretations of complex social phenomena. Symposium conducted at the 32nd annual meeting of the Association for the Advancement of Behavior Therapy, Washington, DC.

Lejuez, C. W., \& Eifert, G. H. (1998, November). A behavioral formulation of hypochondriasis. In C. W. Lejuez (Chair), A behavioral analysis of hypochondriasis: Theoretical, research, and treatment implications. Symposium conducted at the 32nd annual meeting of the Association for the Advancement of Behavior Therapy, Washington, DC.

Lejuez, C. W., Wirth, O., O'Donnell, J. M., Zvolensky, M. J., Eifert, G. H. (1998, March). Avoidance by nonclinical participants: Examining the aversive properties of carbon dioxideenriched air in the laboratory. In M. J. Zvolensky \& C. W. Lejuez (Co-Chairs), Using nonclinical 
populations to elucidate anxiety-related pathological responding. Symposium conducted at the 18th annual meeting of the Anxiety Disorders Association of America, Boston, Ma.

Lejuez, C. W., Zvolensky, M. J., Wirth, O., O'Donnell, J. M., \& Eifert, G. H. (1998, May). Reviving the Experimental Analysis of anxiety using carbon dioxide-enriched air. Paper presented at the 24th annual meeting of the Association for Behavior Analysis, Orlando, Fl.

Zvolensky, M. J., \& Eifert, G. H., \& C. W. Lejuez (1998, March). The influence of control over carbon dioxide-enriched air on anxiety-related responding. In M. J. Zvolensky \& C. W. Lejuez (Co-Chairs), Using nonclinical populations to elucidate anxiety-related pathological responding. Symposium conducted at the 18th annual meeting of the Anxiety Disorders Association of America, Boston, Ma.

Zvolensky, M. J., \& C. W. Lejuez (1998, March, Co-chairs). Using nonclinical populations to elucidate anxiety-related pathological responding. Symposium conducted at the 18th annual meeting of the Anxiety Disorders Association of America, Boston, Ma.

\section{7}

Lejuez, C. W., Eifert, G. H. (1997, May). Conditioned suppression as a function of signaled and unsignaled inhalations of $20 \%$ carbon dioxide-enriched air. In J. C. Crosbie (Chair), Human operant studies of punishment and conditioned suppression. Symposium conducted at the 23rd annual meeting of the Association for Behavior Analysis, Chicago, Ill.

Lejuez, C. W., Eifert, G. H., Zvolensky, M. J., \& Booth, D. E. (1997, March). The role of predictability in the treatment of anxiety: An empirical test using signaled and unsignaled administrations of carbon dioxide-enriched air. In S. G. Hofmann \& D. A. Spiegel (Co-Chairs), Treatment of panic disorder and agoraphobia: Efficacy, cost-effectiveness, and active ingredients. Symposium conducted at the 17th annual meeting of the Anxiety Disorders Association of America, New Orleans, La.

Lejuez, C. W., \& Zvolensky, M. J. (1997, November). Examining the origin and maintenance of anxious responding: Differential effects of controllability and predictability. In M. J. Zvolensky \& C. W. Lejuez (Co-Chairs), Studying anxious responding in the lab: Irrelevant or indispensable? Symposium presented at the 31st annual meeting of the Association for Advancement of Behavior Therapy, Miami, Fla.

Zvolensky, M. J., \& Lejuez, C. W. (1997, November, Co-chairs). Studying anxious responding in the lab: Irrelevant or indispensable? Symposium presented at the 31st annual meeting of the Association for Advancement of Behavior Therapy, Miami, Fla.

\section{6}

Eifert, G. H., \& Lau, A. W., \& Lejuez, C. W. (1996, November). Manualized treatments: The good and the not so good news. In J. P. Forsyth \& R. P. Hawkins (Co-Chairs), Behavior therapy 
at its best and worst. Symposium conducted at the 30th annual meeting of the Association for Advancement of Behavior Therapy, New York, NY.

Forsyth, J. P., \& Lejuez, C. W. (1996, November). The worst of: Taking the "theory" out of behavior therapy. In J. P. Forsyth \& R. P. Hawkins (Co-Chairs), Behavior therapy at its best and worst. Symposium conducted at the 30th annual meeting of the Association for Advancement of Behavior Therapy, New York, NY.

\section{CONFERENCE POSTER PRESENTATIONS}

\section{8}

Hopko, D. R., Lejuez, C. W., McNeil, D. W., \& Barbre, S. D. (1998, November). Behavioral momentum in the treatment of depression. Poster presented at the 32nd annual meeting of the Association for the Advancement of Behavior Therapy, Washington, DC.

Lejuez, C. W., Richards, J. B., Feola, T. W., \& de Wit, H. (1998, October). Discounting of delayed signaled and unsignaled shock. Poster presented at the 16th annual meeting of the Southeastern Association for Behavior Analysis, Asheville, NC.

Lejuez, C. W., Wirth, O., O'Donnell, Zvolensky, M. J., Eifert, G. H. (1997, October). Avoidance of carbon dioxide in the laboratory. Poster presented at the 32nd annual meeting of the Association for the Advancement of Behavior Therapy, Washington, DC.

\section{7}

Lejuez, C. W., Booth, D. E., Forsyth, J. P., \& Eifert, G. H. (1997, May). A device for using carbon dioxide-enriched air as an aversive stimulus: An alternative to shock. Poster presented at the 23rd annual meeting of the Association for Behavior Analysis, Chicago, Ill.

Lejuez, C. W., Forsyth, J. P., Zvolensky, M. J., Heffner, M. P., \& Eifert, G. H. (1997, November). Two devices for administering carbon dioxide-enriched air. Poster presented at the 31st annual meeting of the Association for Advancement of Behavior Therapy, Miami, Fla.

Lejuez, C. W., Heffner, M. P., Zvolensky, M. J., Booth, D. E., \& Eifert, G. H. (1997, November). The differential effects of predictable and unpredictable administrations of $20 \%$ carbon dioxide-enriched air on anxious responding. Poster presented at the 31st annual meeting of the Association for Advancement of Behavior Therapy, Miami, Fla.

Lejuez, C. W., Wirth, O., O'Donnell, Zvolensky, M. J., Eifert, G. H. (1997, October). Avoidance of $20 \%$ carbon dioxide-enriched air with humans. Poster presented at the 15th annual meeting of the Southeastern Association for Behavior Analysis, Chapel Hill, NC.

Zvolensky, M. J., Lejuez, C. W., \& Eifert, G. H. (1997, November). The role of control in panicogenic responding: An experimental test using repeated administrations of $20 \%$ carbon dioxide-enriched air. Poster presented at the 31st annual meeting of the Association for Advancement of Behavior Therapy, Miami, Fla. 
Zvolensky, M. J., Lejuez, C. W., \& Eifert, G. H. (1997, May). The nature of control in carbon dioxide challenge: An experimental test. Poster presented at the American Psychological Society conference, Washington, D.C.

Zvolensky, M. J., Lejuez, C. W., \& Eifert, G. H. (1997, March). Clarifying the nature of control over panic-like events: Is control a risk factor for continued anxious responding. Poster presented at the 17th annual meeting of the Anxiety Disorders Association of America, New Orleans, La.

\section{5}

Lejuez, C. W., \& McDowell, J. J (1995, May). Examination of the residuals produced by a new method of fitting the power function matching equation to concurrent schedule data. Poster presented at the 21st annual meeting of the Association for Behavior Analysis, Washington, DC.

\section{4}

Lejuez, C. W., \& McDowell, J. J (1994, May). A further evaluation of a new method of fitting the power function matching equation to concurrent schedule data. Poster presented at the 20th annual meeting of the Association for Behavior Analysis, Atlanta, GA.

\section{3}

Lejuez, C. W., \& McDowell, J. J (1993, October). Evaluation of a new method of fitting the power function matching equation to concurrent schedule data. Poster presented at the 10th annual meeting of the Southeastern Association for Behavior Analysis, Chapel Hill, NC. 